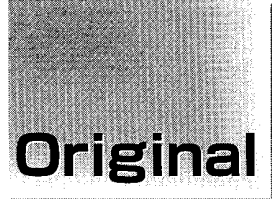

Received June 28, 2005

Revision accepted

Oct. 5, 2005

Code Nos. $\begin{aligned} & 522 \\ & 733\end{aligned}$

\section{Comparison of Gradation Characteristics between Three Typical Medical Imaging Display Devices Using Psychophysical Analysis}

\author{
MASANOBU UEMURA, YOSHIYUKI ASAI, MICHIHIRO \\ YAMAGUCHI, ${ }^{1)}$ YUKO SHINTANI, \\ and SIGERU SANADA ${ }^{2)}$
}

\begin{abstract}
Department of Central Radiology, Kinki University Hospital
1 ) Department of Radiology, Osaka Prefectural Habikino Hospital

2) Department of Radiological Technology, Graduate School of Health Sciences,

Kanazawa University
\end{abstract}

\section{Introduction}

With the recent digitalization of medical images, medical image networking has become common. Although cathode ray tube (CRT) and liquid crystal display (LCD) monitors have been replacing the film/viewer system as image-display devices, the conventional film/ viewer system is still used. In these image-display devices there are large differences in maximal luminance, but no marked differences in image gradation can be visually recognized. To clarify this contradiction, we quantitatively evaluated differences in the gradation characteristics among the above three image-display devices by psychophysical analysis. The threshold con- trast $\left(\mathrm{C}_{\mathrm{t}} \mathrm{s}\right)$ of the image-display devices was measured by the new grayscale test pattern (NGTP), ${ }^{1)}$ and the appropriateness of psychophysical analysis of the CRT and LCD monitors was confirmed. We performed psychophysical analysis of the film/viewer system by converting $\Delta \mathrm{D}_{\min }$ measured by Ozaki et al. ${ }^{2,3)}$ into the difference in luminance. We compared the psychophysical gradients determined in the image-display devices by measuring the minimum perceptible luminance difference $\Delta \mathrm{L}_{\min }$. The usefulness of a theoretical calculation was evaluated by comparing the psychophysical gradient with three models of visual distinguishability.

\title{
Summary
}

Although there are remarkable differences in maximum luminance in cathode ray tube (CRT) and liquid crystal display (LCD) monitors and film/viewer systems, these differences cannot be recognized in our perception of them. To clarify the reason for this conflict, we analyzed the psychophysical gradient $(\delta)$, which is based on the minimum perceptible luminance difference $\left(\Delta \mathrm{L}_{\min }\right)$ and can express contrast visually recognized by observers. In this study, we first confirmed the compatibility of the psychophysical analysis to the CRT and the LCD monitors by using their threshold contrasts $\left(\mathrm{C}_{t} \mathrm{~s}\right)$. Second, we calculated and compared the $\delta$ 's of the above output devices. The $\mathrm{C}_{\mathrm{t}} \mathrm{s}$ values of each device were in good agreement. Moreover, the Moon \& Spencer model, which expressed the perceptibility of luminance change, was well suited to the measured $C_{t}$ s over the whole luminance range. The psychophysical analysis is therefore available not only for the film/viewer system, but also for the CRT and LCD systems. The difference of physical gradient G of the luminance characteristics curve among the output devices was larger than 20 times, whereas that of $\delta$ was within 3 times. The display devices listed in the order of decreasing $\delta$ were film/viewer $>$ LCD $>C R T$. These results corresponded to the visual contrast sensation and our clinical experience, which cannot recognize remarkable differences in perception. By using the psychophysical analysis, we clarified the reason for the conflict between the results of physical evaluation and the contrast visually recognized by observers.

Key words: Psychophysical gradient, Threshold contrast, Minimum perceptible luminance difference, Psychophysical analysis

別刷資料請求先：=589-0014 大阪狭山市大野東377-2

近畿大学医学部附属病院 中央放射線部 上村正信 宛 


\section{Materials and Methods}

\section{1-1 Comparison of threshold contrast}

This study was performed in three steps. First, the minimum perceptible luminance difference $\Delta \mathrm{L}_{\min }$ was measured in the film/viewer system and in the CRT and LCD monitors by use of the NGTP, as shown in Fig. 1, and the $\mathrm{C}_{\mathrm{t}} \mathrm{s}$ of each luminance was determined. $\Delta \mathrm{L}_{\text {min }}$ agrees with the concept of Just Noticeable Difference (JND), which was proposed by Digital Imaging and Communications in Medicine (DICOM). The minimum perceptible luminance difference, $\Delta \mathrm{L}_{\min }$, was determined by 8 radiologists with healthy vision using a luminance meter (Minolta LS-100) to examine the limit of the noticeable luminance between two segments at various luminance levels. The results were compared with three models (Weber, Moon \& Spencer, and Barten) for calculation of the $\mathrm{C}_{t} \mathrm{~s},{ }^{4,5)}$ and the applicability of psychophysical analysis using the luminance to devices with a different image-display system was evaluated.

As shown in Fig. 1, the NGTP comprises $256 \mathrm{seg}$ ments consisting of $16 \times 16$ squares, without gaps, and each segment shows one gradation step. The difference between 2 gradation steps is equivalent to a CT value of 16 , and the 256 steps agree with 4,096 CT values between $-1,024$ and 3,071 . The NGTP is a 12 -bit grayscale pattern. The LCD monitor was a black-andwhite monitor of 1 megapixel(precision 1, Data Ray Corp., USA) with a graphic card (ATI Technologies Inc., USA). The digital input and output in this monitor were 8 bits and 11 bits, respectively, at a maximal luminance of $450 \mathrm{~cd} / \mathrm{m}^{2}$, and the minimal difference in luminance between 2 segments was $0.2 \mathrm{~cd} / \mathrm{m}^{2}$. The CRT monitor was a color monitor with an output of 8 bits at a maximal luminance of $125 \mathrm{~cd} / \mathrm{m}^{2}$ (Barco MWD321 Plus Medical Workstation Display, BARCO, USA).

The monitoring conditions were an observation distance of $25 \mathrm{~cm}$ and target luminance of $0.05-450 \mathrm{~cd} / \mathrm{m}^{2}$. To prevent the effects of glare, light sources around the target were covered with black paper. The observation was performed after adaptation to the darkroom. To evaluate $\Delta \mathrm{L}_{\min }$, the examiners were allowed to change the window and level. The $\Delta \mathrm{L}_{\text {min }}$ of the film/viewer system was obtained from data of the step edge shown in Figs. $3(\mathrm{a})-(\mathrm{c})$ reported in 1995 by Matsumoto et al. ${ }^{6}$ Since the threshold is expressed as diffuse density units, we converted the minimum perceptible contrast $\Delta D_{\min }$ into $\Delta \mathrm{L}_{\min }$ with equation ( 1 ).

$$
\Delta \mathrm{L}_{\min }=\mathrm{L}\left(10^{\Delta \mathrm{Dmin} / 2}-10^{-\Delta \mathrm{Dmin} / 2}\right)
$$

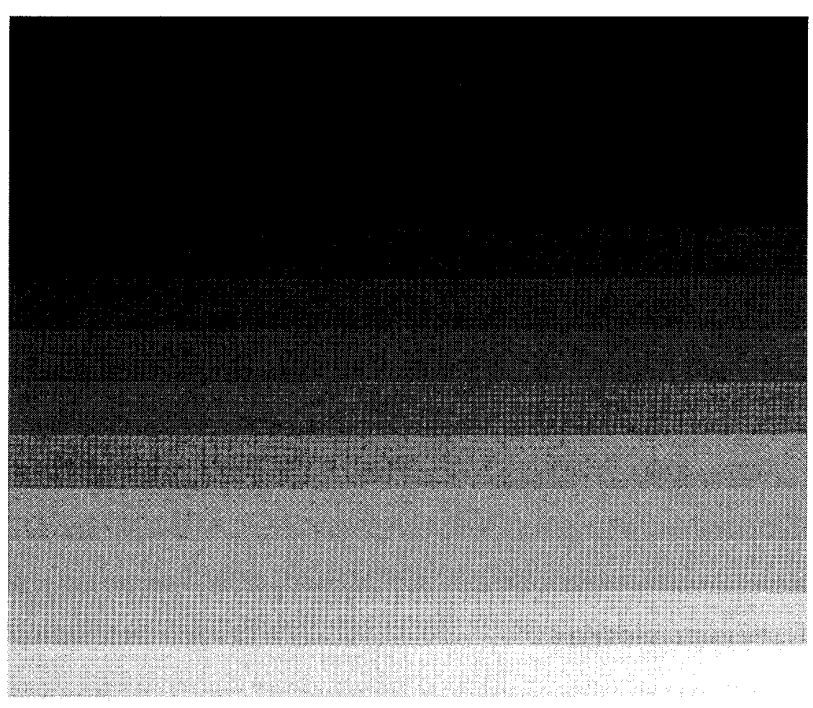

Fig. 1 New grayscale test pattern (NGTP) used in this study.

where $\mathrm{L}$ denotes the luminance after transmission through film.

Figure 2 shows the relationship between the general sinusoidal pattern and contrast. ${ }^{7,8)}$ Contrast is expressed by equation (2).

$$
\mathrm{C}_{\mathrm{s}}=\left(\mathrm{L}_{\max }-\mathrm{L}_{\min }\right) /\left(\mathrm{L}_{\max }+\mathrm{L}_{\min }\right)=\Delta \mathrm{L}_{\mathrm{cp}} / \mathrm{L}
$$

where $\mathrm{L}$ and $\Delta \mathrm{L}_{\mathrm{cp}}$ are luminance and the difference in luminance between the center and peak level in the sinusoidal pattern, respectively. In Fig. 2, when the amplitude of the sinusoidal pattern is just at the threshold level of visual perception, the luminance difference between the peak-to-peak levels is called the minimum perceptible luminance difference $\Delta \mathrm{L}_{\text {min }}$. This is because we perceive objects, including the sinusoidal pattern, by always using the difference between the maximum and minimum luminance. When the relationship between $\Delta \mathrm{L}_{\mathrm{cp}}$ and $\Delta \mathrm{L}_{\mathrm{min}}$ is considered, threshold contrast, $\mathrm{C}_{\mathrm{t}}$, is expressed by equation (3).

$$
\mathrm{C}_{\mathrm{t}}=\Delta \mathrm{L}_{\min } / 2 \mathrm{~L}
$$

where $\Delta \mathrm{L}_{\min }$ denotes the minimum perceptible luminance difference.

Therefore, the $\mathrm{C}_{t} \mathrm{~s}$ of the three image-displaying systems are determined by substituting $\Delta \mathrm{L}_{\min }$ values for equation (3).

To evaluate the appropriateness of the $\Delta \mathrm{L}_{\min } \mathrm{val}$ ues determined by the use of equation ( 3 ), we compared the $\mathrm{C}_{\mathrm{t}} \mathrm{s}$ of the three image-displaying systems to that determined by the use of equation (4) in the Moon \& Spencer 
model, ${ }^{9)}$ which shows human visual distinguishability.

$$
\left.\Delta \mathrm{L}_{\min }=0.0123(0.808 \sqrt{\mathrm{L}})^{2 / 2 \mathrm{~L}}\right)
$$

\section{1-2 Comparison of the gradation characteristics}

The NGTP was displayed on the CRT and LCD monitors, and the luminance $(\mathrm{L})$ of the $\mathrm{CT}$ value in each step was measured by a luminance meter, and the gradient $(G)$ was calculated from the luminance characteristic curve. In the film/viewer system, the density measured by a diffuse densitometer was converted into the luminance by equation (5).

$$
\mathrm{L}=\mathrm{L}_{0} \times 10^{\mathrm{D}}
$$

where $\mathrm{D}$ denotes the mean density of film, $\mathrm{L}$ the luminance transmitted through film with a density of $\mathrm{D}$, and $\mathrm{L}_{0}$ the luminance of the show box. $\mathrm{L}_{0}=2,550 \mathrm{~cd} / \mathrm{m}^{2}$ was used in this study.

\section{1-3 Psychophysical analysis}

In a psychophysical analysis, the psychophysical contrast is obtained by multiplying physical contrast by a modulation transfer function (MTF) of the human eye. When the MTF of the human eye expressed using the peak-to-peak of the sinusoidal pattern is regarded as $T_{e}$, $T_{e}$ is defined as the inverse of $C_{t}$, as shown in this equation $^{10)}(6)$.

$$
\mathrm{T}_{\mathrm{e}}=\mathrm{C}_{\mathrm{t}}^{-1}=2 \mathrm{~L} / \Delta \mathrm{L}_{\min }
$$

According to the relationship between equations (2) and $(3)$, the physical contrast $\left(C_{p}\right)$ of the consecutive two segments, as shown in Fig. 1, is expressed as

$$
\mathrm{C}_{\mathrm{p}}=\Delta \mathrm{L}_{\mathrm{pp}} / 2 \mathrm{~L}
$$

where $\mathrm{L}$ denotes the mean luminance of the sinusoidal pattern, and $\Delta \mathrm{L}_{\mathrm{pp}}$ is the difference in physical luminance. Therefore, the visual contrast sensation $(S)$ is expressed as the psychophysical contrast by equation (8).

$$
\mathrm{S}=\Delta \mathrm{L}_{\mathrm{pp}} / 2 \mathrm{~L} \times 2 \mathrm{~L} / \Delta \mathrm{L}_{\min }=\Delta \mathrm{L}_{\mathrm{pp}} / \Delta \mathrm{L}_{\min }
$$

When the difference in the luminance between two segments is very small, $\Delta \mathrm{L}_{\mathrm{pp}}$ is proportional to the gradient $\mathrm{G}$ of the CT value-luminance curve. Therefore, the psychophysical gradient $\delta$ is expressed by equation(9).

$$
\delta=\mathrm{G} / \Delta \mathrm{L}_{\min }
$$

The minimum perceptible luminance difference $\Delta \mathrm{L}_{\min }$ is a function of the luminance, and the psycho-

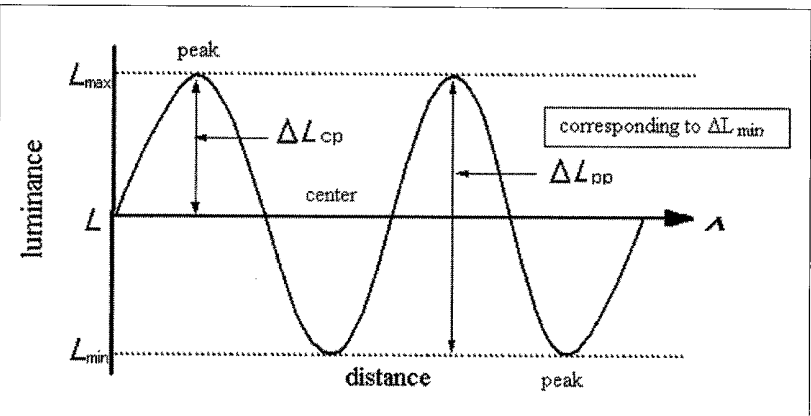

Fig. 2 Relationship between $\Delta \mathrm{L}_{c p}$ and $\Delta \mathrm{L}_{p p}$ in the sinusoidal pattern used for the definition of physical contrast and visual perception of objects, respectively. When amplitude is just at the threshold level of visual perception, $\Delta \mathrm{L}_{p p}$ is called $\Delta \mathrm{L}_{\text {min }}$.

physical gradient $\delta$ is determined by substituting the luminance for equation (9). The psychophysical gradient $\delta$ was used as the main parameter of the psychophysical gradation characteristics in the image-display systems. ${ }^{11}$ )

\section{Results}

\section{2-1 Comparison of the threshold contrast}

Figure 3 shows the $C_{t} s$ measured in the film/viewer system and in the LCD and CRT monitors along with the $\mathrm{C}_{\mathrm{t}} \mathrm{s}$ determined by use of the three models. Although there were marked differences in the available luminance range between the three image-display devices, the $C_{t} s$ indicated in the same luminance range were in good agreement. Among the three models of visual distinguishability of the luminance, the $\mathrm{C}_{\mathrm{t}} \mathrm{s}$ determined by use of the Moon \& Spencer model showed good agreement throughout the entire luminance range with that obtained by measurement.

\section{2-2 Comparison of the gradation characteristics}

Figure 4 shows the input and output characteristics of each image-display device. In the entire CT-value range (luminance range), luminance was highest in the film/ viewer system, which was at maximum about 4-fold higher than that in the LCD monitor and about 20-fold higher than that in the CRT monitor.

\section{2-3 Comparison of the psychophysical gradient}

Figure 5 shows the psychophysical gradient $\delta$ determined by use of the CT-value. In the entire luminance range, $\delta$ was highest in the film/viewer system, followed by the LCD and CRT monitors. The differences were large in the low luminance range, but they were 2- to 3fold higher in the film/viewer system than in the CRT 


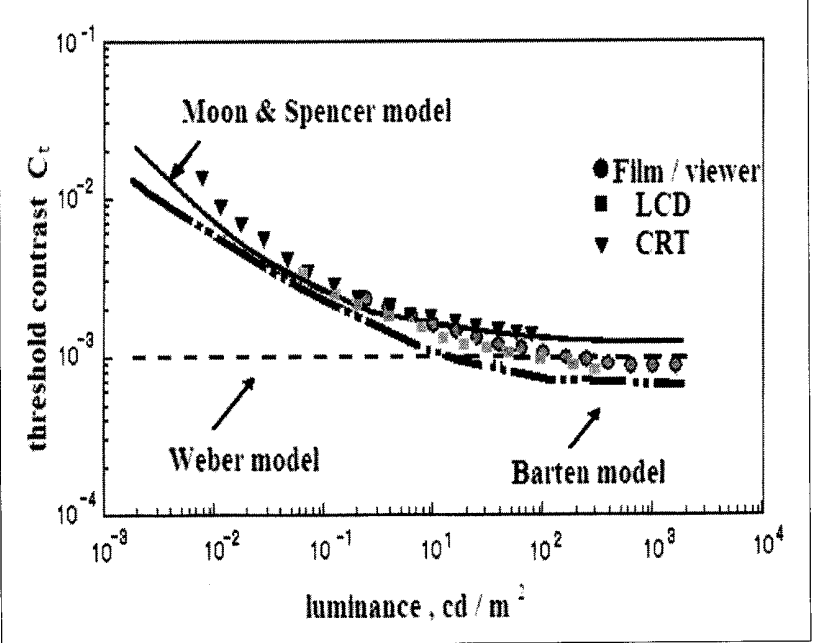

Fig. 3 Threshold contrasts $C_{t} s$ as a function of luminance $\mathrm{L}$ for the film/viewer system (O), CRT $(\boldsymbol{\nabla}), \operatorname{LCD}(\boldsymbol{\square})$, and the fitting curve obtained by the Moon \& Spencer model (solid line), Weber model (dashed line), and Barten model(two-dot chain line).

monitor. In the high luminance range, the psychophysical gradient in the LCD monitor was similar to that in the film/viewer system.

\section{Discussion}

The main result of this study was confirmation of the compatibility of psychophysical analysis used for the conventional film/viewer system with LCD and CRT monitors. Since differences in the image-display method and the available luminance range are large among these image-display devices, we measured their minimum perceptible luminance difference $\Delta \mathrm{L}_{\min }$ values and determined the $C_{t} s$. As shown in Fig. 3, the contrast in the three image-display devices agreed well in the luminance range common to them. Because the $\mathrm{C}_{\mathrm{t}} \mathrm{s}$ calculated by use of the Moon \& Spencer model showed good agreement throughout the entire luminance range with that obtained by measurement, the psychophysical gradient based on the minimum perceptible luminance difference $\Delta \mathrm{L}_{\text {min }}$ values was considered to be applicable to devices with different image-display methods. With regard to the input and output characteristics, as shown in Fig. 4, there was a 20-fold difference in luminance between the film/viewer system and the CRT monitor, but we failed to macroscopically recognize such a large difference, indicating that it is difficult to perform an accurate evaluation when using input and output characteristics obtained by physical measurement. However, as shown in Fig. 5, the psychophysical gradient in the CRT monitor was only

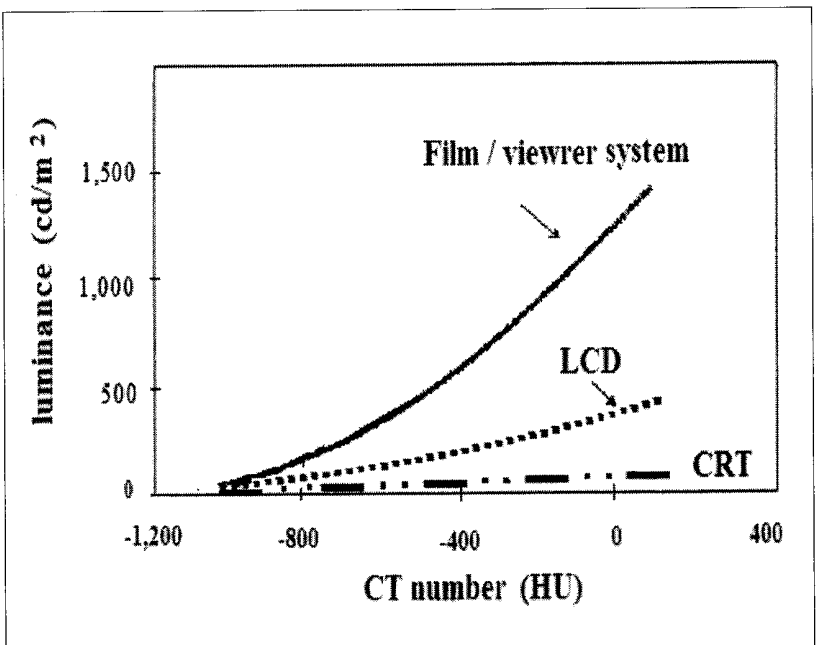

Fig. 4 Luminance $L$ as a function of the CT number for the film/viewer system (solid line), CRT (two-dot chain line), and LCD (dashed line), which are measured by NGTP. Window width and window level settings are 1,600 and -550 , respectively.

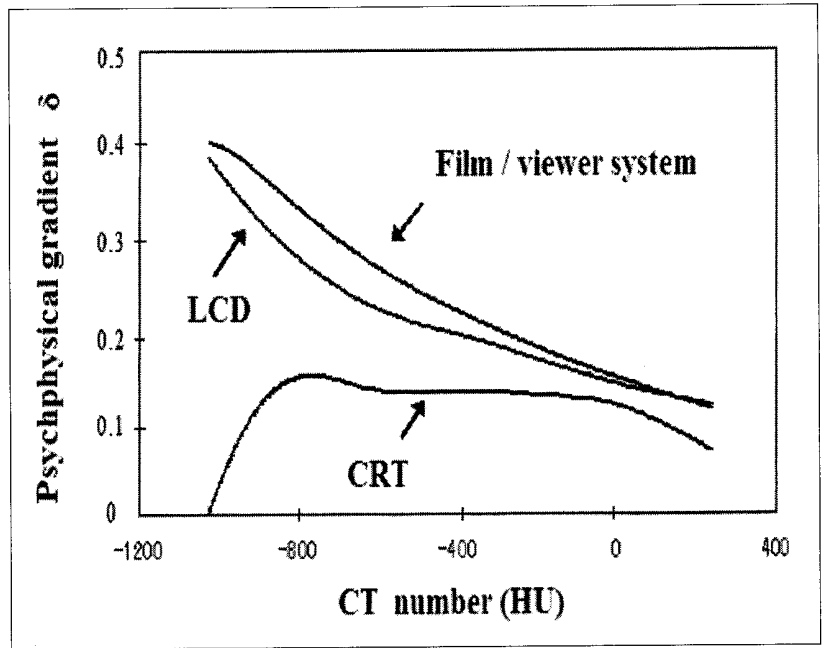

Fig. 5 Psychophysical gradients as a function of the CT number for the film/viewer system, CRT, and LCD. Window width and window level settings are 1,600 and -550 , respectively.

2- to 3 -fold lower than that in the film/viewer system, and in the LCD monitor it was similar to that in the film/ viewer system, which was in close agreement with our recognition. These results mean that the psychophysical gradient $\delta$ is dependent on the maximum luminance. However, the difference in $\delta$ between the film/viewer system and LCD monitor was smaller than that of $\delta$ between the CRT monitor and LCD monitor. This may be because images are displayed on the LCD monitor, using the luminance range immediately before changes in $\mathrm{C}_{t} \mathrm{~s}$ reach equilibrium, as shown in Fig. 3 . 


\section{Conclusion}

Using psychophysical analysis, we determined the reason for the conflict between the results of physical evaluation and the contrast visually recognized by observers. The differences in psychophysical gradient between the three typical kinds of display devices were within approximately 3 times. This result corresponds closely to the visual contrast sensation and our clinical experience, which cannot recognize a remarkable difference in perception.

\section{References}

1) Yamaguchi M, Fujita $H$, Uemura $M$, et al.: Development and evaluation of a new gray-scale test pattern to adjust gradients of thoracic CT imaging. European Radiology, 14, 2357 2361, (2004).

2) Ozaki Y, Kubota H, Matsumoto M, et al.: Frequency dependence of minimum perceptible contrasts and optimum film densities of radiographs. J Photogr Sci, 41, 59-62, (1993).

3) Ozaki Y, Kubota H, Matsumoto M, et al.: Frequency dependence of minimum perceptible contrasts of radiographs and MTF of the eye. J Photogr Sci, 41 96-97, (1993).

4) Barten PGJ.: Physical model for the contrast sensitivity of the human eye. Proc SPIE 1666, 57-72,(1992).

5) Barten PGJ: Spatio-temporal model for the contrast sensitivity of the human eye and its temporal aspects. Proc SPIE 1913, 2-14, (1993).

6) Matsumoto M, Ozaki Y, Kubota H, et al.: Equivalent spatial frequency and optimum film densities for the perceptibility of radiographic contrast of step-edge images. J Photogr Sci,
43, 99-102, (1995).

7) "Digital Imaging and Communications in Medicine (DICOM) Part 14: Grayscale Standard Display Function", National Electrical Manufacturers Association, Rosslyn, Virginia USA, 1-14,(1999)

8) De Palma JJ, and Lowry EM: Sine-wave response of the visual system II. Sine-wave and square wave sensitivity. J Opt Soc Amer, 52, 328-335, (1962).

9) Moon P, and Spencer DE: Visual effect of non-uniform surrounds. J Opt Soc Amer, 35, 233-238, (1945).

10) Patel AS: Spatial resolution by the human visual system: the effect of mean retinal illuminance. J Opt Soc Amer, 56, 689694, (1966).

11) Asai Y, Shintani Y, Yamaguchi M, et al: Evaluation of greyscale standard display function as a calibration tool for diagnostic liquid crystal display monitors using psychophysical analysis. Med Biol Eng Computing, 43, 319-324, (2005).

Fig. 1 使用した12bitグレイスケールテストパターン (NGTP)

Fig. 2 正弦波コントラストパターンにおける物理コントラストと視覚の識別域の定義を用いた $\Delta \mathrm{L}_{\mathrm{cp}}$ と $\Delta \mathrm{L}_{\mathrm{pp}}$ の関係。振幅が視覚の 閾值に一致するとき $\Delta \mathrm{L}_{\mathrm{pp}}$ は最小識別輝度差 $\Delta \mathrm{L}_{\min }$ と呼ばれる。

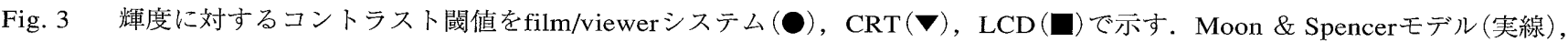
Weberモデル(点線)，Barten モデル(二点鎖線)で示す.

Fig. 4 NGTPを用いた画像表示装置のCT值に対する輝度出力特性

film/viewerシステム (実線)，CRT (二点鎖線)，LCD(点線)で示す：window width (1600)，window level (-550)

Fig. 5 film/viewerシステム，CRT，LCDのCT值に対する心理物理的グラジェント $\delta$ : window width $(1,600)$, window level(-550) 